\title{
Research on Library Management System Based on Java
}

\author{
Shasha Yu, Enhai Qiu and Mei Zhou \\ Jiangxi Industry Polytechnic College, Nanchang, 330099
}

\section{Keywords: Java; Library management system; Database design; Books; Management}

\begin{abstract}
With the need of informationization and modernization of colleges, more and more colleges choose to move towards the direction of digital library management. As a transmission center of information in colleges, library plays a vital role in the dissemination of knowledge and spiritual civilization. The level of library construction is closely related to the quality of teaching in colleges. In the 1990s, with the increasing enrollment, more and more students enter into the university, increasingly updated information and technology rushed to society, it becomes more urgent for students desire to understand new knowledge and technology, while solving this urgent need can not be solved depending on the classroom teaching. The library's old management methods can not adapt to the development of the times, in order to better solve this contradiction, we found that carry out optimization and the upgrade to the management of the library, moving to its automated management, then better meet the needs of colleges and students demand.
\end{abstract}

\section{Introduction}

With the rapid development of computer technology, the application of computer technology in all walks of life has been widely popular. The development of modern information technology has led to the progress of the library in the direction of automation, network and digitization. Due to the increase in the collection of library books and the increasing demand for information, the traditional manual management methods have many shortcomings, the main performance is that the efficiency of handling of borrowing books and returning books process is very low, obviously it can not adapt to the current information society. The library business has been impacted greatly, forcing people to intensify toopen the new information management methods to manage the pace of books in order to improve efficiency, reduce staff work pressure and reduce the probability of error, but also allows readers to have more time to choose books and read books. Book management system is a typical information management system, how to use the existing scientific and technological conditions to improve the management efficiency of books is our urgent problem to be considered and solved. This paper combined the basic requirements of modern library management system, discussed the specific process of system developmentin detail, including feasibility analysis, demand analysis, system design, database design and coding test and other links. It basically meet the requirements of the daily management of small libraries, to achieve the desired design goals.

\section{Introduction of Java}

Java was developed by a team of James Gosling, Sun Microsystems. Originally called Oak, it was designed in 1991 for embedded customer electronics applications. In 1995, it was renamed Java,redesigned to develop Internet applications. Java programs can be embedded in HTML pages, downloaded by the Web browser, bringing animation and exchange of enjoymentfor the Web customers. BecauseJava is free, as well as simple, cross-platform, object-oriented and many other advantages, has quickly been recognized by this industry, becoming the most widely applied programming language.

Because it is a common programming language, Java's powerful features are not limited to Web applications. Its programming capabilities are complete and can be used to develop separate applications. Java is inherently object oriented. Although many object-oriented languages were originally a strict procedural language, Java was designed from the beginning to be object-oriented. 


\section{Library Management System Requirements Analysis}

In order to realize a simple and full-featured book inventory management information system, through the communication with the library staff, made an in-depth analysis on the basic functions of inventory management, holding the basic ideas of first phase of the construction, firstlyproviding a basic library inventory management system. On the whole, the inventory management system needs to be able to provide inventory management, book borrowing andreturning functions, the basic management functions of library managers and the user's quick query and retrieval function.

Based on the overall functions of library inventory management information system, the functions of the system are divided into several aspects. The inventory management system is divided from the point of view of functions, including library storage, library management, book circulation management, statistical query function, the corresponding functional requirements were shown in Fig. 1.

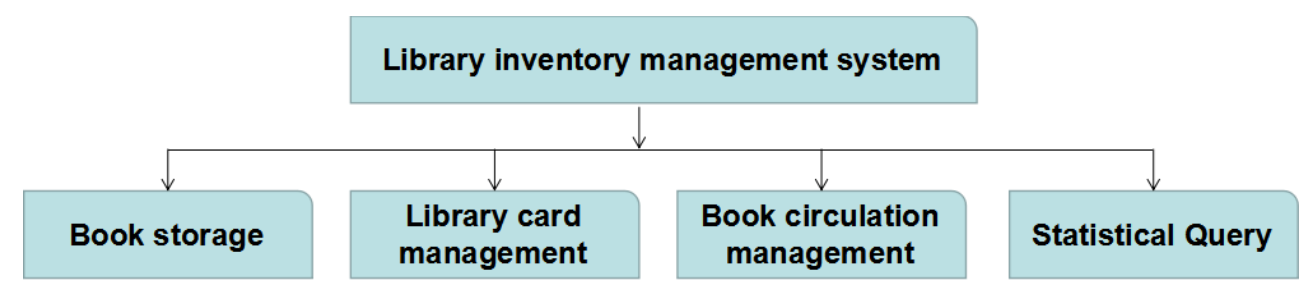

Figure 1. Finite Library inventory management system function requirements map

Book storage function is the basis of the library inventory management system, through this function to achievethe storage operation for all books, mainly for the new purchased books, therefore, books need to provide basic information on books, including this book name, bar code, author, classification number, category name, shelf number, press, publication date, storage date and book price and other information. In the process of storage it should be provided the add, delete, revoke and other functions, to achieve the process of storage changes and other operations.

\section{Database Conception Design}

According to the above analysis of the needs analysis, the system design to planthe database entities used in the system, they are book information entities, book classification entities, readers information entities, operator information entities, book borrowing information entities, inventory information entities, respectively. The book information entity and the book classification entity, the book borrows the information entity, the storage information entity have the relation, while the reader information entity and the book borrowing entity also have the relation. Here are the E-R diagrams for several key entities.

Book information entity includes the book number, book category number, title, author, translator, publisher, price, publishing time and other attributes. Therein, the book number is the primary key of the book information entity, the book category number is the foreign key of the book information entity, and the book type entity has the outside key relation. Book information entity E-R diagram was shown in Fig. 2.

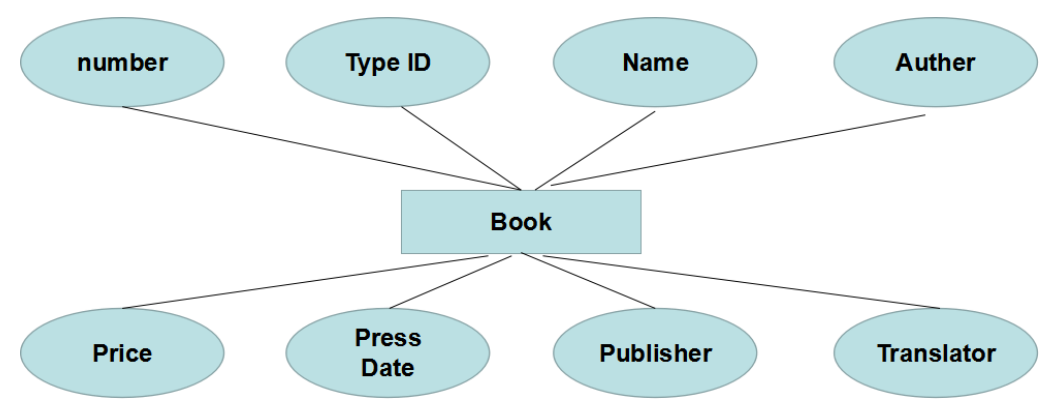

Figure 2. Finite Book information entity E-R diagram 


\section{System Overall Design}

In order to meet the requirements of university library informatization, the system adopts ApacheTomcat + SQLServer. The system design follows the principle of separating the business logic and system from the current software industry. The hierarchical implementation not only strengthens the flexibility and scalability of the whole product,but also enhance the independence of the system modules, if a module layer changes, it will not affect the other module layer, greatly enhancing the entire product maintainability and flexibility.

The system design first needs to make the corresponding module division. Based on the basis of the requirement of file management system management, the system is divided into three parts: file retrieval function module, file management function module, system management function module.

(1) File retrieval module -Retrieve file by conditions: Search condition includes file name (fuzzy search), file level (exact search), file description (fuzzy search);

(2) File management module - by department structure management file: department structure can be managed through the system management settings, specific operations, including archiving file upload, view, delete.

(3) System management module - mainly realize department management, user management, rights management, file level management.

\section{Design of the Partial Module of System}

System management module is the core of the entire system, the general operation of the module can only be carried out by the system administrator, such that the staff need to have this power, they must get the authority of the administrator. System management module specific functional structure was shown in Fig. 3, the administrator can enter the login interface.There are four sub-modules in the system management module, namely the department management module, the user management module, the rights management module and the file level management module.

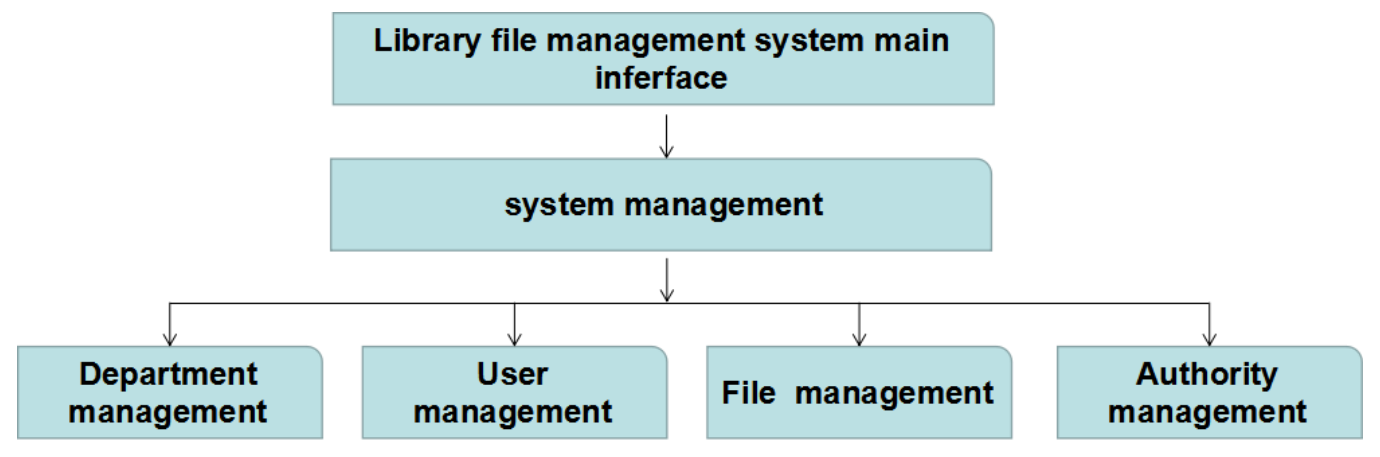

Figure 3. Finite The structural image of system management module

\section{The Design of Privilege Management Module}

The module is the core of all modules, making settings for the file and user permissions, you can do the following operations: view (de-fault.jsp), permissions setting (qxiant.jsp). The module is mainly on the user's permissions setting, you can set the permissionlevel of user to read the file, set the contents that can be viewed. To achieve the rights management module function of the source program is as follows:

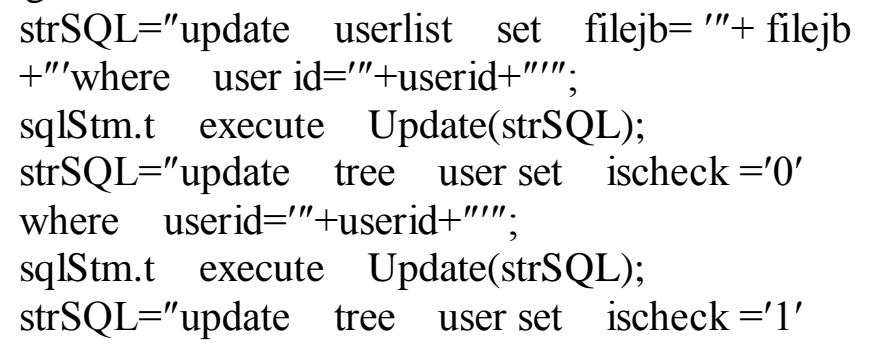


where userid $=$ "'+userid + "'and left(id,4) in $\left("+\mathrm{isC}+{ }^{\prime \prime}\right)$ ";

qlStm.t executeUpdate(strSQL);

strSQL $=$ "update tree users et ischeck $=^{\prime} 1^{\prime}$

where userid $={ }^{\prime \prime}+$ userid $+" '$ and id in $("+\mathrm{isB}+") "$;

qlStm.t execute Update(strSQL).

\section{Conclusion}

This paper studied and implemented the library management system. In the modern information management of computer technology, network technology and database technology, the library management system has become an important part of the information construction of colleges. The library has become the information center and hub of the university, The library's digital construction on the agenda has become extremely urgent. This paper mainly did the following research:

1.Studied the importance of the database system to the whole project structure design, Java's advantage, My SQL has the characteristics of small size, fast speed and low cost, so as to provide a solution for the realization of the system prototype.

2.Studied the classification requirements of current library to the system function, which we divided it into the system administrator management module, user management module, and made an interpretation on some of the modules of the task.

3.Completed the realization of the library management system, improve the efficiency of library management, people and the resources get a reasonable optimization, reducing the cost of library management.

\section{References}

[1] Roknuzzaman M, Kanai H, Umemoto K. Integration of knowledge management process into digital library system[J]. Library Review, 2013, 58(5):372-386.

[2] Fu P, Fitzgerald M. A Comparative Analysis of the Effect of the Integrated Library System on Staffing Models in Academic Libraries[J]. Information Technology \& Libraries, 2013, 32:47-58.

[3] Seena S T, Pillaiw K G S. A study of ICT skills among library professionals in the Kerala University Library System[J]. Annals of Library \& Information Studies, 2014, 61(2).

[4] Taole N, Dick A L. Implementing a common library system for the Lesotho Library Consortium[J]. Electronic Library, 2013, 27(1):5-19.

[5] Chen M, Cai W, Ma L. Cloud Computing Platform for an Online Model Library System[J]. Mathematical Problems in Engineering,2013,(2013-4-17), 2013, 2013(1):532-546.

[6] Hall K, Ames C M, Brice J. Open Source Library Software Development in a Small Rural Library System[J]. Code4lib Journal, 2013, 19(19):1-10.

[7] Uppal V, Chindwani G. An Empirical Study of Application of Data Mining Techniques in Library System[J]. Journal of Bacteriology, 2014, 74(11):42-46.

[8] Rao N S, Kumari N N. Revitalisation of Public Library System in India: A CSR Perspective[J]. Desidoc Journal of Library \& Information Technology, 2013, 33(1):25-28.

[9] Kumar R S, Kaliyaperumal K. Applications of GSM technology for documents identification in a library system[J]. Library Philosophy \& Practice, 2014(1159).

[10] Haslam M, Kwon M L, Marilyn M P, et al. The automated storage and retrieval system (ASRS) in Lied Library[J]. Library Hi Tech, 2013, 20(1):71-89.

[11] Pu Y H, Chiu P S, Chen T S, et al. The design and implementation of a Mobile Library APP system[J]. Library Hi Tech, 2015, 33(1):15-31.

[12] Iorio A D, Schaerf M. The Organization information integration in the management of a Digital Library System[C]// Digital Libraries. IEEE, 2014:461-462. 